\title{
Proteomic analysis of differential protein expression by brain metastases of gynecological malignancies
}

\author{
Ayako Yoshida $\cdot$ Naoki Okamoto $\cdot$ Akiko Tozawa-Ono • \\ Hirotaka Koizumi · Kazushige Kiguchi · \\ Bunpei Ishizuka · Toshio Kumai · Nao Suzuki
}

Received: 2 October 2012/ Accepted: 29 October 2012/Published online: 16 March 2013

(C) The Author(s) 2013. This article is published with open access at Springerlink.com

\begin{abstract}
Brain metastases of gynecological malignancies are rare, but the incidence is increasing. Patients with brain metastases have a poor prognosis, therefore early detection and optimal management is necessary. In order to determine a new biomarker, we aimed to identify proteins that associated with brain metastases. We investigated proteins associated with brain metastases of gynecological malignancies in three patients who underwent surgical resection (stage IIb cervical cancer, stage Ib endometrial cancer, and stage IIIb ovarian cancer). Proteomic analysis was performed on formalin-fixed paraffin-embedded (FFPE) samples of the primary tumors and brain metastases, which were analyzed by liquid chromatography with tandem mass spectrometry. Thereafter, candidate proteins were identified by the Scaffold system and Mascot search program, and were analyzed using western blotting and immunohistochemistry. As a result, a total of 129 proteins were identified. In endometrial and ovarian cancers, western blotting revealed that the expression of alpha-enolase (ENO1) and triosephosphate isomerase (TPI-1) was higher and the expression of Transgelin-2 (TAGLN2) was lower in metastatic tumors than in primary tumors. On the other
\end{abstract}

A. Yoshida $\cdot$ N. Okamoto $\cdot$ A. Tozawa-Ono $(\bowtie)$.

K. Kiguchi · B. Ishizuka · N. Suzuki

Department of Obstetrics and Gynecology, St. Marianna

University School of Medicine, 2-16-1 Sugao,

Miyamae-ku, Kawasaki, Kanagawa 216-8511, Japan

e-mail: a2ono@marianna-.ac.jp

H. Koizumi

Department of Diagnostic Pathology, St. Marianna University

School of Medicine, Kanagawa 216-8511, Japan

T. Kumai

Graduate School of Pharmacogenomics, St. Marianna University

School of Medicine, Kanagawa 216-8511, Japan hand, the expression of TPI-1 and TAGLN2 was lower in metastatic tumors than in primary tumors in cervical cancer. Immunohistochemistry confirmed that ENO1 expression was elevated in the metastatic tumors compared with the primary tumors. In conclusion, the present study showed that FFPE tissue-based proteomics analysis can be powerful tool, and these findings suggested that ENO1, TPI-1, and TAGLN2 may have a role in the development and progression of brain metastasis from gynecological malignancies.

Keywords Brain metastasis - Gynecological malignancies $\cdot$ Alpha-enolase $\cdot$ Triosephosphate isomerase . Transgelin-2

\section{Introduction}

The incidence rate of gynecological malignancies is increasing in Japan, but mortality is stable due to more effective treatment and better diagnostic techniques. However, the treatment of advanced cancer remains problematic [1]. Metastasis is a major cause of morbidity and mortality in cancer patients, so investigation of the mechanisms involved is very important. Metastasis of cancer cells is a highly selective and non-random process that comprises a series of linked events. Various molecular and genetic changes define the multistep process of tumor dissemination, which has been described as the "metastatic cascade" [2]. Hematogenous metastasis is a complex biological process that includes the steps of intravasation, transport in the blood, extravasation, and growth in a distant organ [3]. For hematogenous metastasis to occur, every step of the cascade must be completed [4]. According to the "seed and soil" theory of Paget, organ selectivity 
of metastasis is based on the interaction between tumor cells (the "seed") and the microenvironment of the target organ (the "soil"), which supports extravasation, survival, and growth of the metastatic tumor [5]. Metastasis of gynecological malignancies can occur via the lymphatic, hematogenous, and transcoelomic routes. For cervical cancer, the most frequent sites of metastasis are the lungs, paraaortic lymph nodes, supraclavicular lymph nodes, and abdominal cavity [6]. For endometrial cancer, the most frequent sites are the lung and liver, followed by other sites such as the adrenal gland, breast, bone, skin, and brain [7]. In the case of ovarian cancer, transcoelomic metastasis is the most common, followed by pelvic lymph node, peritoneal, lymphatic, and, rarely, by hematogenous spread [8]. Metastasis to the brain is one of the most feared complications of cancer, since patients with brain metastasis usually have a poor prognosis and rapidly progressive neurologic symptoms. Consequently, treatment of brain metastases is becoming an increasingly important determinant of the survival time and quality of life for cancer patients, meaning that early detection and optimal management of brain metastases are essential. According to the brain tumor registry of Japan (1984-1996), tumors of the lung $(52.3 \%)$, breast $(8.9 \%)$, and rectum $(5.2 \%)$ are most likely to metastasize to the brain, while brain metastasis from gynecological malignancies is rare $(1.7 \%$ for uterine cancer and $0.8 \%$ for ovarian cancer) [9]. However, a recent study suggested that the incidence of brain metastasis from gynecological malignancies is rising along with the longer survival of patients with these tumors due to effective treatment and the availability of better imaging techniques [10].

DNA microarray analysis has now become a standard tool for molecular studies of cancer [11]. The ability to complement this approach with methods of proteomic analysis [12] is crucial for identification of proteins that may serve as targets for new antibody-based therapeutic strategies [13]. Such proteomic research is particularly important for the characterization of gene products contributing to the metastatic potential of cancer [14]. Molecular screening of metastases by proteomic analysis has been done in several previous studies, including investigations of breast cancer, hepatocellular carcinoma, and squamous cell carcinoma of the lung [15-17]. However, there has been little proteomic analysis of clinical samples of gynecological malignancies, including brain metastases.

Therefore, the present study was performed to investigate differential protein expression in patients with brain metastases of gynecological malignancies using proteomic analysis with the hope of identifying potential new tumor markers. To do this, we performed a comparative proteomic analysis of primary and metastatic tumor tissue sample from patients with gynecological cancer by liquid chromatography with tandem mass spectrometry (LC-MS/MS).

\section{Materials and methods}

Proteomic analysis was performed on formalin-fixed paraffin-embedded samples of primary tumors and brain metastases, which were analyzed by LC-MS/MS. Candidate proteins were detected using the Scaffold system and Mascot search program. The expression of some proteins was also assessed by western blotting and immunohistochemistry.

\section{Patients}

We reviewed 15 patients with brain metastases of gynecological malignancies. Between 2005 and 2009, 3 of them underwent surgical resection, including 1 patient each with uterine cervical cancer (FIGO stage IIb), endometrial cancer (FIGO stage Ib), and ovarian cancer (FIGO stage IIIb) (Table 1). Tumor tissue samples were fixed in $10 \%$ buffered formalin for 24-48 $\mathrm{h}$ and then were embedded in paraffin, after which blocks of these specimens were stored from 2005 to 2009. The study protocol was approved by the Human Ethics Review Committee of St. Marianna University School of Medicine.

\section{Extraction of proteins from tumor tissues}

To minimize contamination of samples by stromal cells, we selected the block that contained the largest amount of tumor tissue from each patient. Extraction of crude proteins from these tissue blocks was carried out as described elsewhere [18], with minor modifications. Briefly, 10 tissue sections (each $10 \mu \mathrm{m}$ thick) were deparaffinized in $1 \mathrm{~mL}$ of xylene with gentle agitation for $5 \mathrm{~min}$. After removing the xylene, $1 \mathrm{~mL}$ of $100 \%$ ethanol was added and the sections were agitated for $5 \mathrm{~min}$. After centrifugation at $15,000 \mathrm{~g}$ for $10 \mathrm{~min}$, the supernatant was removed and the pellet was thoroughly dried under a vacuum for $10 \mathrm{~min}$. Then, $100 \mu \mathrm{l}$ of extraction buffer from the Qproteome FFPE Tissue Kit (Qiagen, Valencia, CA, USA) was added to the dewaxed tissue pellet, followed by incubation on ice for $5 \mathrm{~min}$, vortex mixing, and heating at $100{ }^{\circ} \mathrm{C}$ for $20 \mathrm{~min}$ and $80{ }^{\circ} \mathrm{C}$ for $2 \mathrm{~h}$ in a Thermomixer at $750 \mathrm{rpm}$. After centrifugation at $14,000 \mathrm{~g}$ and $4{ }^{\circ} \mathrm{C}$ for $15 \mathrm{~min}, 10 \mu \mathrm{L}$ of the supernatant was used to measure the protein content by the Lowry method [19].

\section{Sample preparation and LC-MS/MS}

For isolation of tissues and preparation of proteins, the Qproteome FFPE Tissue Kit (Qiagen) was employed according to the manufacturer's recommendations. After the total protein content was measured by the Lowry method, protein samples $(50 \mu \mathrm{g})$ were divided up for LCMS/MS analysis. These protein samples were digested with 
Table 1 Clinical characteristics of the patients

\begin{tabular}{|c|c|c|c|}
\hline & \multicolumn{3}{|l|}{ Patients } \\
\hline & 1 & 2 & 3 \\
\hline Diagnosis & $\mathrm{EC}$ & $\mathrm{CeC}$ & $\mathrm{OC}$ \\
\hline FIGO stage & $\mathrm{Ib}$ & $\mathrm{IIb}$ & $\mathrm{IIIb}$ \\
\hline Histology & Endometrioid adenocarcinoma, G1 & Squamous cell carcinoma & Serous adenocarcinoma \\
\hline Primary treatment & $\begin{array}{l}\text { Modified radical } \\
\text { hysterectomy }+ \text { BSO + PLN + chemotherapy }\end{array}$ & $\begin{array}{l}\text { Radical } \\
\text { hysterectomy + CCRT }\end{array}$ & $\begin{array}{l}\text { Total } \\
\text { hysterectomy }+ \text { BSO }+ \text { omentectomy }+ \text { chemotherapy }\end{array}$ \\
\hline $\begin{array}{l}\text { Number of brain } \\
\text { metastases }\end{array}$ & 1 & 1 & 1 \\
\hline $\begin{array}{l}\text { Treatment of brain } \\
\text { metastasis }\end{array}$ & Surgery + WBRT & Surgery + WBRT & Surgery + WBRT \\
\hline $\begin{array}{l}\text { Other sites of } \\
\text { disease }\end{array}$ & None & $\begin{array}{l}\text { LN (paraaortic, } \\
\text { Virchow's) pulmonary }\end{array}$ & Abdominal \\
\hline Survival $^{\text {a }}$ (months) & AWD (48) & DOD (22) & DOD (4) \\
\hline
\end{tabular}

$E C$ endometrial cancer, $C e C$ uterine cervical cancer, $O C$ ovarian cancer, $C C R T$ concurrent chemoradiotherapy, $B S O$ bilatelal salpingo-oophorectomy, $P L N$ pelvic lymph node dissection, $L N$ lymph node, WBRT whole brain radiotherapy, $A W D$ alive with disease, $D O D$ dead of disease

a Survival from diagnosis of brain metastasis

trypsin (Protease MAX Surfactant; Promega, Madison, WI, USA) and then extracted with a Zip tip $\mathrm{C}_{18}$ pipette tip (Promega).

The resulting peptides were subjected to LC-MS/MS analysis using a capillary LC system (Magic2002; Michrom BioResources, Auburn, CA, USA) coupled to an inline nanoelectrospraymass spectrometer (LCQAdvantage; Thermo Finnegan, Waltham, MA, USA) with a silica-coated glass capillary tube (PiclTip; New Objective, Woburn, MA, USA) to obtain a peptide mass fingerprint. Raw LC-MS/MS data files were searched by both Mascot and X!Tandem for identification. To generate a statistically valid list of proteins, Scaffold was used to accommodate differences of algorithm and score calculation by the two search engines [20]. Each protein identified was assigned a biological process based on information from the international protein index (IPI) human database (European Bioinformatics Institute, 2011) and the Gene Ontology (GO) database (National Center for Biotechnology Information, 2011).

\section{Western blotting}

Protein samples ( $10 \mu \mathrm{g}$ each) were mixed in sample buffer at $100{ }^{\circ} \mathrm{C}$ for $5 \mathrm{~min}$ and subjected to SDS-polyacrylamide gel electrophoresis on $10 \%$ polyacrylamide gels. Then, the samples were transferred to enhanced chemiluminescence membranes (ECL; Amersham-Pharmacia Biotech, Buckinghamshire, UK) that had been blocked for $1 \mathrm{~h}$ in ECL Advance Blocking Agent. These membranes were incubated with rabbit anti-transgelin-2 (TAGLN2) polyclonal antibody (1:200; Sigma, Saint Louis, MO, USA), rabbit anti-triosephosphate isomerase 1 (TPI-1) polyclonal antibody (1:200; GeneTex, Irvine, CA, USA), or rabbit anti-enolase 1 (ENO1) polyclonal antibody (1:250; Abcam, Cambridge, UK) for $1 \mathrm{~h}$ at room temperature. After washing for a total of $30 \mathrm{~min}$ with 5 exchanges of Tris buffered saline with Tween 20 (TBS-T), the membranes were incubated with peroxidase-labeled immunoglobulin $\mathrm{G}$ of the appropriate species for $1 \mathrm{~h}$ at room temperature. After washing a further 5 times with TBS-T, immunoreactive proteins were detected with an ECL Advance Western Blotting Detection System kit (AmershamPharmacia Biotech, Piscataway, NJ, USA) and an LAS3000(Fujifilm, Tokyo, Japan). After stripping, the membranes were reprobed with mouse anti-actin monoclonal antibody (1:2,000; Sigma) as a loading control.

Immunohistochemistry

Tissue blocks of the primary tumors and brain metastases were cut into $3-\mu \mathrm{m}$ sections, which were dewaxed, rehydrated, and incubated with $3 \%$ hydrogen peroxide for 5 min to block endogenous peroxidases. Then, the sections were incubated with anti-ENO1 monoclonal antibody (1:100; Abcam) at room temperature for $1 \mathrm{~h}$. After washing 3 times with phosphate-buffered saline, the sections were incubated with a horseradish peroxidase-labeled polymerconjugated anti-mouse secondary antibody (ENVISION + ; Dako, Copenhagen, Denmark) for $30 \mathrm{~min}$ at room temperature. Finally, color was developed with 3,3'diaminobenzidine tetrahydrochloride.

\section{Results}

Proteins identified in the primary and metastatic tumors

Raw files of LC-MS/MS data were searched by both Mascot and X!Tandem for identification of proteins. To 
Table 2 List of total expressed protein (protein identification probability)

\begin{tabular}{|c|c|c|c|c|c|c|c|}
\hline \multirow[t]{3}{*}{ No. } & \multirow[t]{3}{*}{ Protein name } & \multicolumn{6}{|c|}{ Observed sample (probability \%) } \\
\hline & & \multicolumn{3}{|c|}{ Primary tumor } & \multicolumn{3}{|c|}{ Metastatic tumor } \\
\hline & & $\mathrm{EC}$ & $\mathrm{CeC}$ & $\mathrm{OC}$ & $\mathrm{EC}$ & $\mathrm{CeC}$ & $\mathrm{OC}$ \\
\hline 1 & Actin, cytoplasmic 1 & 100 & 100 & 100 & 100 & 100 & 100 \\
\hline 2 & Histone $\mathrm{H} 4$ & 100 & 100 & 100 & 100 & 100 & 100 \\
\hline 3 & Keratin, type II cytoskeletal 1 & 100 & 90 & 100 & 100 & 100 & 100 \\
\hline 4 & Hemoglobin subunit beta & 100 & 100 & 100 & 89 & 100 & 100 \\
\hline 5 & Histone H1.2 & 100 & 100 & 89 & 100 & 100 & \\
\hline 6 & Uncharacterized protein & 93 & 100 & 98 & 100 & & 100 \\
\hline 7 & Hemoglobin subunit alpha & 93 & 100 & 100 & 89 & 100 & 89 \\
\hline 8 & Histone $\mathrm{H} 2 \mathrm{~A}$ type $1-\mathrm{B} / \mathrm{E}$ & 100 & 100 & 89 & 100 & 100 & 89 \\
\hline 9 & Tubulin, beta & & & 100 & 100 & 100 & 100 \\
\hline 10 & Keratin, type I cytoskeletal 10 & 93 & 100 & & 100 & 100 & 89 \\
\hline 11 & Glyceraldehyde-3-phosphate dehydrogenase & 100 & 90 & 100 & 100 & 100 & 100 \\
\hline 12 & Histone H3.2 & 100 & 90 & 89 & 94 & 100 & 89 \\
\hline 13 & Histone $\mathrm{H} 2 \mathrm{~B}$ type $1-\mathrm{L}$ & 98 & 99 & 89 & 89 & 99 & \\
\hline 14 & Isoform alpha-enolase of Alpha-enolase & & & 100 & 100 & 100 & 100 \\
\hline 15 & Triosephosphate isomerase isoform 2 & 99 & & & 100 & 100 & 98 \\
\hline 16 & Vimentin & & & 100 & & 90 & 100 \\
\hline 17 & IGL@protein & & 100 & & 89 & 90 & 89 \\
\hline 18 & TUBA1C protein & & & 89 & & 100 & 98 \\
\hline 19 & Keratin, type I cytoskeletal 9 & 100 & & & 99 & & \\
\hline 20 & Beta-actin-like protein 2 & & 90 & 89 & & 90 & 89 \\
\hline 21 & Neutrophil defensin 1 & 93 & 90 & & 100 & 90 & \\
\hline 22 & Isoform M1 of Pyruvate kinase isozymes M1/M2 & & 90 & & & 100 & 98 \\
\hline 23 & Heat shock protein beta- 1 & & 100 & 89 & & 90 & \\
\hline 24 & Ubiquitin-40S ribosomal protein $\mathrm{S} 27 \mathrm{a}$ & & 90 & & 99 & & \\
\hline 25 & Nuclease-sensitive element-binding protein 1 & 93 & 90 & & 89 & & 89 \\
\hline 26 & $23 \mathrm{kDa}$ protein & 93 & & & 89 & 90 & 89 \\
\hline 27 & Keratin, type I cytoskeletal 19 & 93 & & & 89 & 90 & 89 \\
\hline 28 & Collagen alpha-2(I) chain & 93 & 90 & 89 & 89 & & \\
\hline 29 & Protein S100-A8 & 100 & 90 & & & 90 & \\
\hline 30 & Heat shock $70 \mathrm{kDa}$ protein $1 \mathrm{~A} / 1 \mathrm{~B}$ & & & 89 & 89 & 100 & \\
\hline 31 & Protein S100-A9 & & 100 & & 100 & & \\
\hline 32 & Isoform 1 of Fibronectin & 93 & 90 & & 89 & & \\
\hline 33 & Galectin-1 & 93 & 90 & & 89 & & \\
\hline 34 & Isoform 1 of L-lactate dehydrogenase A chain & 93 & & & 89 & 90 & \\
\hline 35 & PRO2275 & & 90 & 89 & 89 & & \\
\hline 36 & $60 \mathrm{~S}$ ribosomal protein $\mathrm{L} 8$ & 43 & 90 & & & 90 & \\
\hline 37 & $\mathrm{~N}$-acetyltransferase ESCO2 & 89 & & & 35 & 90 & \\
\hline 38 & cDNA FLJ45139 fis, clone BRAWH3039623 & & 88 & & 30 & 90 & \\
\hline 39 & $40 \mathrm{~S}$ ribosomal protein $\mathrm{S} 25$ & 93 & & & & 90 & \\
\hline 40 & Isoform 1 of Heterogeneous nuclear ribonucleoprotein $\mathrm{K}$ & 93 & & & & 90 & \\
\hline 41 & Uncharacterized protein & 93 & & & & & 89 \\
\hline 42 & $14-3-3$ protein theta & 93 & & & 89 & & \\
\hline 43 & Putative annexin A2-like protein & 93 & & & 89 & & \\
\hline 44 & Peptidyl-prolyl cis-trans isomerase A & 93 & & & 89 & & \\
\hline 45 & Fructose-bisphosphate aldolase A & 93 & & & 89 & & \\
\hline 46 & Glutathione S-transferase P & & 90 & & & 90 & \\
\hline
\end{tabular}


Table 2 continued

\begin{tabular}{|c|c|c|c|c|c|c|c|}
\hline \multirow[t]{3}{*}{ No. } & \multirow[t]{3}{*}{ Protein name } & \multicolumn{6}{|c|}{ Observed sample (probability \%) } \\
\hline & & \multicolumn{3}{|c|}{ Primary tumor } & \multicolumn{3}{|c|}{ Metastatic tumor } \\
\hline & & EC & $\mathrm{CeC}$ & $\mathrm{OC}$ & $\mathrm{EC}$ & $\mathrm{CeC}$ & $\mathrm{OC}$ \\
\hline 47 & Profilin-1 & & & 89 & & & 89 \\
\hline 48 & Histone $\mathrm{H} 2 \mathrm{~A}$ type $2-\mathrm{B}$ & & 86 & & & & 89 \\
\hline 49 & Isoform B1 of Heterogeneous nuclear ribonucleoproteins A2/B1 & & & & 100 & 90 & 73 \\
\hline 50 & Isoform 1 of Glial fibrillary acidic protein & & & & & 90 & 100 \\
\hline 51 & Ubiquitin-like modifier-activating enzyme 1 & & & & & & 100 \\
\hline 52 & Elongation factor 1 -alpha 1 & & & & & 100 & \\
\hline 53 & Beta-2-microglobulin & & & & & 90 & 89 \\
\hline 54 & 14-3-3 protein zeta/delta & & & & & 90 & 89 \\
\hline 55 & Isoform Long of 14-3-3 protein beta/alpha & & & & 89 & 90 & \\
\hline 56 & ATP synthase subunit alpha, mitochondrial & & & & 89 & 90 & \\
\hline 57 & Putative uncharacterized protein & & & & 89 & 90 & \\
\hline 58 & Fibrinogen beta chain & & & & 100 & & \\
\hline 59 & Heat shock protein HSP 90-beta & & & & & & 100 \\
\hline 60 & Keratin, type I cytoskeletal 18 & & & & & & 100 \\
\hline 61 & Isoform 1 of heterogeneous nuclear ribonucleoprotein $\mathrm{A} 3$ & & & & & 100 & \\
\hline 62 & Stress-70 protein, mitochondrial & & & & & & 100 \\
\hline 63 & Keratin, type II cytoskeletal 8 & & & & & & 100 \\
\hline 64 & ATP synthase subunit beta, mitochondrial & & & & & & 100 \\
\hline 65 & Peroxiredoxin-1 & & & & & 90 & \\
\hline 66 & Histone $\mathrm{H} 1 \mathrm{x}$ & & & & & 90 & \\
\hline 67 & $60 \mathrm{~S}$ ribosomal protein $\mathrm{L} 7 \mathrm{a}$ & & & & & 90 & \\
\hline 68 & Isoform short of heterogeneous nuclear ribonucleoprotein $U$ & & & & & 90 & \\
\hline 69 & Isoform 3 of probable ATP-dependent RNA helicase DDX17 & & & & & 90 & \\
\hline 70 & Homeobox protein HMX3 & & & & & 90 & \\
\hline 71 & Isoform 1 of tropomyosin alpha- 4 chain & & & & & & 89 \\
\hline 72 & Isocitrate dehydrogenase [NADP], mitochondrial & & & & & & 89 \\
\hline 73 & Poly(rC)-binding protein 1 & & & & & & 89 \\
\hline 74 & Thioredoxin-dependent peroxide reductase, mitochondrial & & & & & & 89 \\
\hline 75 & NHP2-like protein 1 & & & & & & 89 \\
\hline 76 & Phosphoglycerate kinase 1 & & & & & & 89 \\
\hline 77 & Elongation factor 2 & & & & & & 89 \\
\hline 78 & Thioredoxin & & & & & & 89 \\
\hline 79 & Phosphoglycerate mutase 2 & & & & & & 89 \\
\hline 80 & Isoform 1 of clusterin & & & & & & 89 \\
\hline 81 & Isoform mitochondrial of fumarate hydratase, mitochondrial & & & & & & 89 \\
\hline 82 & Isoform 2 of protein disulfide-isomerase A6 & & & & & & 89 \\
\hline 83 & Isoform 1 of 3,2-trans-enoyl-CoA isomerase, mitochondrial & & & & & & 89 \\
\hline 84 & Isoform 2 of heterogeneous nuclear ribonucleoprotein $\mathrm{A} / \mathrm{B}$ & & & & & & 89 \\
\hline 85 & Keratin, type II cytoskeletal $1 \mathrm{~b}$ & & & & & & 89 \\
\hline 86 & $32 \mathrm{kDa}$ protein & & & & & & 89 \\
\hline 87 & Hemoglobin subunit delta & & & & & & 89 \\
\hline 88 & $14 \mathrm{kDa}$ protein & & & & & & 89 \\
\hline 89 & Isoform 1 of heat shock cognate $71 \mathrm{kDa}$ protein & & & & 89 & & \\
\hline 90 & Histone $\mathrm{H} 2 \mathrm{~B}$ type $2-\mathrm{E}$ & & & & 89 & & \\
\hline 91 & Plasminogen & & & & 89 & & \\
\hline 92 & Keratin, type II cytoskeletal 2 epidermal & & & & 89 & & \\
\hline
\end{tabular}


Table 2 continued

\begin{tabular}{|c|c|c|c|c|c|c|c|}
\hline \multirow[t]{3}{*}{ No. } & \multirow[t]{3}{*}{ Protein name } & \multicolumn{6}{|c|}{ Observed sample (probability \%) } \\
\hline & & \multicolumn{3}{|c|}{ Primary tumor } & \multicolumn{3}{|c|}{ Metastatic tumor } \\
\hline & & $\mathrm{EC}$ & $\mathrm{CeC}$ & $\mathrm{OC}$ & $\mathrm{EC}$ & $\mathrm{CeC}$ & $\mathrm{OC}$ \\
\hline 93 & Isoform 1 of heterogeneous nuclear ribonucleoprotein D0 & & & & 89 & & \\
\hline 94 & ADP-ribosylation factor 1 & & & & 89 & & \\
\hline 95 & Isoform A1-B of heterogeneous nuclear ribonucleoprotein A1 & & & & 89 & & \\
\hline 96 & Isoform $\mathrm{C} 1$ of heterogeneous nuclear ribonucleoproteins $\mathrm{C} 1 / \mathrm{C} 2$ & & & & 89 & & \\
\hline 97 & Isoform 1 of myelin proteolipid protein & & & & 89 & & \\
\hline 98 & $14-3-3$ protein gamma & & & & 89 & & \\
\hline 99 & Isoform 1 of brain acid soluble protein 1 & & & & 89 & & \\
\hline 100 & cDNA FLJ35730 fis, clone TESTI2003131, highly similar to ALPHA-1-ANTICHYMOTRYPSIN & & & & 89 & & \\
\hline 101 & Isoform 2 of Nucleophosminisoform 2 of nucleophosmin & & & & 89 & & \\
\hline 102 & Myosin light chain 6B & 93 & 90 & 89 & & & \\
\hline 103 & $60 \mathrm{~S}$ ribosomal protein $\mathrm{L} 7$ & 93 & 99 & & & & \\
\hline 104 & Histone H1.5 & 93 & 98 & & & & \\
\hline 105 & Transgelin & & 100 & & & & \\
\hline 106 & Phosphatidylethanolamine-binding protein 1 & 93 & 90 & & & & \\
\hline 107 & Transgelin-2 & & 90 & 89 & & & \\
\hline 108 & Isoform long of splicing factor, proline- and glutamine-rich & 93 & & & & & \\
\hline 109 & 40S ribosomal protein $\mathrm{S} 14$ & 93 & & & & & \\
\hline 110 & Myosin regulatory light chain $12 \mathrm{~B}$ & 93 & & & & & \\
\hline 111 & 40S ribosomal protein $\mathrm{S} 13$ & 93 & & & & & \\
\hline 112 & Isoform 1 of Protein shisa- 6 homolog & 93 & & & & & \\
\hline 113 & Histone H2A.V & & 90 & & & & \\
\hline 114 & Lumican & & 90 & & & & \\
\hline 115 & Prolargin & & 90 & & & & \\
\hline 116 & HLA class I histocompatibility antigen, $\mathrm{Cw}-1$ alpha chain & & 90 & & & & \\
\hline 117 & Isoform 2 of microtubule-actin cross-linking factor 1 , isoforms $1 / 2 / 3 / 5$ & & 90 & & & & \\
\hline 118 & Macrophage migration inhibitory factor & & 90 & & & & \\
\hline 119 & Isoform 1 of FYVE, RhoGEF and PH domain-containing protein 5 & & 90 & & & & \\
\hline 120 & $31 \mathrm{kDa}$ protein & & 90 & & & & \\
\hline 121 & Centrosomal protein $170 \mathrm{kDa}$ & & 90 & & & & \\
\hline 122 & Isoform 1 of DNA polymerase theta & & 90 & & & & \\
\hline 123 & Isoform 1 of serine/arginine-rich splicing factor 7 & & & 89 & & & \\
\hline 124 & Heterogeneous nuclear ribonucleoprotein $\mathrm{H}$ & & & 89 & & & \\
\hline 125 & Hypothetical protein LOC80164 & & & 89 & & & \\
\hline 126 & Acyl-CoA-binding domain-containing protein 7-like & & & 89 & & & \\
\hline 127 & NOL1/NOP2/Sun domain family member 4 & & & 89 & & & \\
\hline 128 & Actin, alpha skeletal muscle & & 90 & & & & \\
\hline 129 & 60S ribosomal protein L31 & 93 & & & & & \\
\hline
\end{tabular}

Protein expression profiles of metastatic and primary tumor determined by LS/MS/MS. List of proteins found differentially expression between brain metastatic tumor and primary tumor. Protein identification probability is shown by the percentage of total spectra

$E C$ Endometrial cancer, $C e C$ uterine cervical cancer, $O C$ ovarian cancer

generate a statistically valid protein list, Scaffold was used to accommodate differences of algorithm and score calculation between the two search engines [20]. A total of 129 proteins were identified (76 in the primary tumors and 101 in the metastatic tumors) (Table 2). Comparison of the primary and metastatic tumors revealed the differential expression of 81 proteins ( 28 in the solely primary tumors and 53 in the solely metastatic tumors) and the shared expression of 48 other proteins (Fig. 1a). 


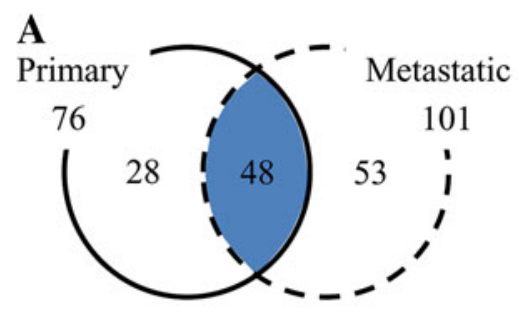

B
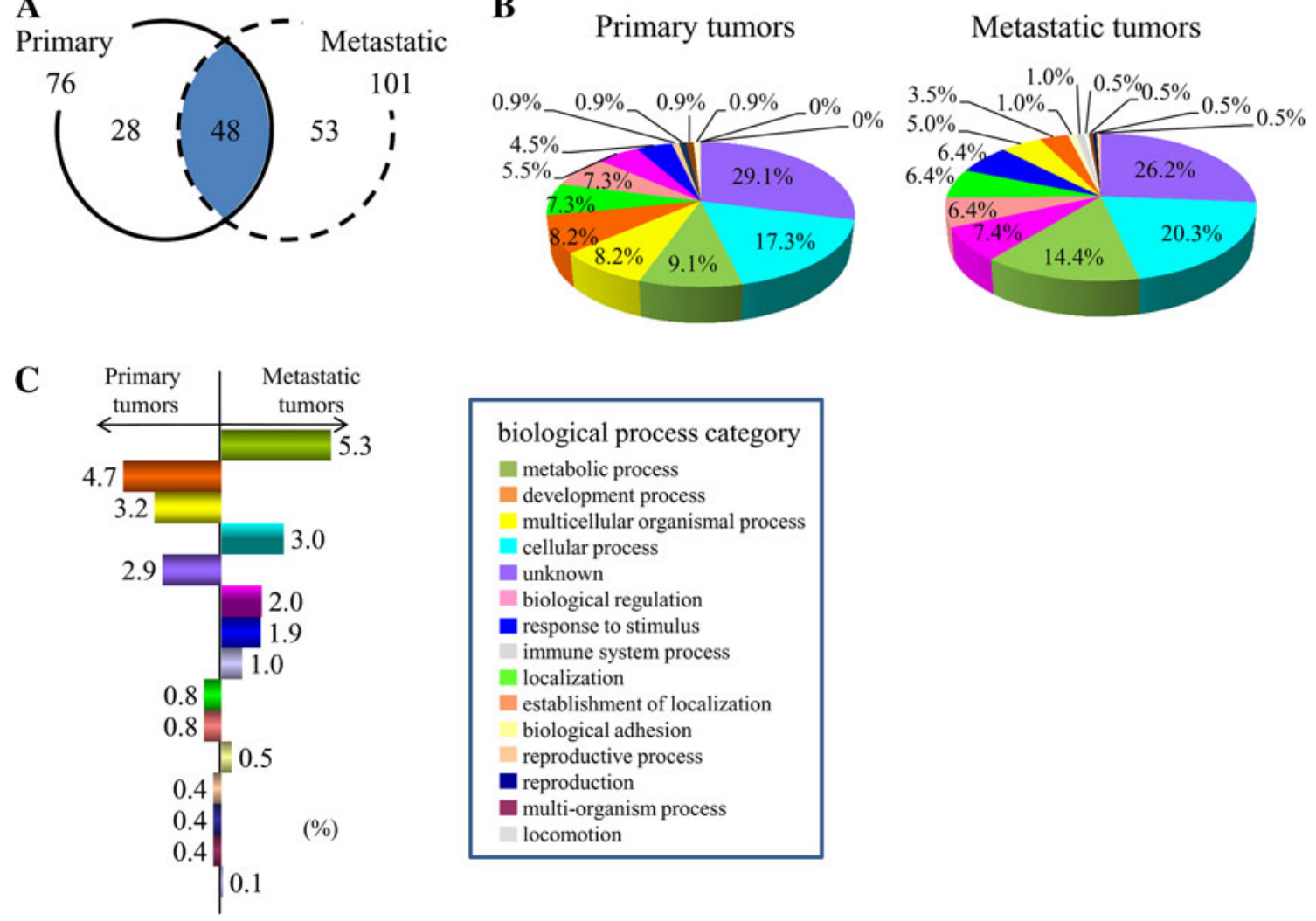

Fig. 1 Protein expression in primary and metastatic tumors. a Venn diagram showing the differential expression of 129 proteins by primary and metastatic tumors (76 in primary tumors and 101 in metastatic tumors). b Distribution of proteins related to different biological processes. $\mathbf{c}$ Comparison of proteins expressed by primary

Proteomes of the primary and metastatic tumors

Each protein that we identified was assigned a biological process based on information from the IPI and GO databases to understand their role. If a protein was known to participate in more than one biological process, it was included in multiple categories. Classification according to biological processes showed that the majority of the proteins were involved in metabolic processes, developmental processes, or multicellular organismal process (Fig. 1b), with some interesting proteins that have been implicated in tumorigenesis. In metastatic tumors, proteins related to developmental and multicellular organismal process were decreased compared with primary tumors (4.7 and $3.2 \%$, respectively), while proteins related to metabolic processes were increased compared with primary tumors $(5.3 \%)$ (Fig. 1c).

Differential protein expression by primary and metastatic tumors

Comparison of the distribution of proteins between primary and metastatic tumors revealed differences of proteins and metastatic tumors. The expression of proteins related to developmental and multicellular organismal process was lower in metastatic tumors than in primary tumors, whereas the expression of proteins related to metabolic processes was higher in metastatic tumors than in primary tumors

involved in metabolic, developmental, and multicellular organismal processes (Fig. 1c). Based on the results of searches carried out in the primary and metastatic tumors, eight candidate proteins were selected (Table 3). Among these proteins, TAGLN2, TPI-1, and ENO1 were subjected to further investigation.

\section{Confirmation of differential protein expression}

To more precisely evaluate TAGLN2, TPI-1, and ENO1 expression by gynecological cancers, western blotting was carried out using proteins extracted from the 3 primary and 3 metastatic tumors. In endometrial and ovarian cancers, the expression of TPI-1 and ENO1 was higher in metastatic tumors than in primary tumors; this finding was consistent with the reported role of these proteins in promoting tumor cell survival and proliferation [21, 22]. However, the expression of TAGLN2 was lower in metastatic tumors than in primary tumors; this finding was consistent with the reported role of TAGLN2 as a tumor suppressor [23]. Further, in cervical cancer, the expression of TAGLN2 and TPI-1 was lower in metastatic tumors than in primary tumors (Fig. 2). 
Table 3 Protein expression profile of the primary and metastatic tumors

\begin{tabular}{|c|c|c|c|c|c|c|c|c|c|}
\hline \multirow[t]{3}{*}{ Protein category } & \multirow[t]{3}{*}{ Gene } & \multirow[t]{3}{*}{$\mathrm{p} I$} & \multirow[t]{3}{*}{ MW } & \multicolumn{6}{|c|}{ Observed sample (Mascot score) } \\
\hline & & & & \multicolumn{3}{|c|}{ Primary tumors } & \multicolumn{3}{|c|}{ Metastatic tumors } \\
\hline & & & & $\mathrm{EC}$ & $\mathrm{CeC}$ & $\mathrm{OC}$ & $\mathrm{EC}$ & $\mathrm{CeC}$ & $\mathrm{OC}$ \\
\hline \multicolumn{10}{|l|}{ Metabolic process } \\
\hline Triosephosphate isomerase 1 & TPI1 & 5.7 & 30.8 & $+(111)$ & & - & $+(200)$ & $+(96)$ & $+(60)$ \\
\hline Alpha-enolase & ENO1 & 7.0 & 47.1 & - & - & $+(112)$ & $+(206)$ & $+(94)$ & $+(28)$ \\
\hline ATP synthase subunit alpha, mitochondrial & ATP5A & 9.2 & 59.7 & - & - & - & $+(62)$ & $+(72)$ & - \\
\hline Tubulin beta & TUBB & 7.8 & 47.0 & - & - & $+(58)$ & $+(96)$ & $+(124)$ & $+(97)$ \\
\hline 60 S ribosomal protein $\mathrm{L} 7$ & RPL7 & 10.7 & 29.2 & $+(63)$ & $+(59)$ & - & - & - & - \\
\hline \multicolumn{10}{|l|}{ Developmental precess } \\
\hline Myosin light chain 6B & MYL6 & 5.6 & 22.8 & $+(52)$ & - & $+(75)$ & - & - & - \\
\hline Transgelin-2 & TAGLN2 & 8.4 & 22.4 & - & $+(66)$ & $+(86)$ & - & - & - \\
\hline \multicolumn{10}{|l|}{ Multicellular organismal process } \\
\hline Phosphatidylethanolamine-binding protein 1 & PEBP1 & 8.6 & 26.4 & $+(40)$ & $+(35)$ & - & - & - & - \\
\hline
\end{tabular}

Probabilities of 95 and $80 \%$ were used as the cutoff values for identification of peptides and proteins, respectively, excluding proteins identified with a lesser probability

$E C$ Endometrial cancer, $C e C$ uterine cervical cancer, $O C$ ovarian cancer

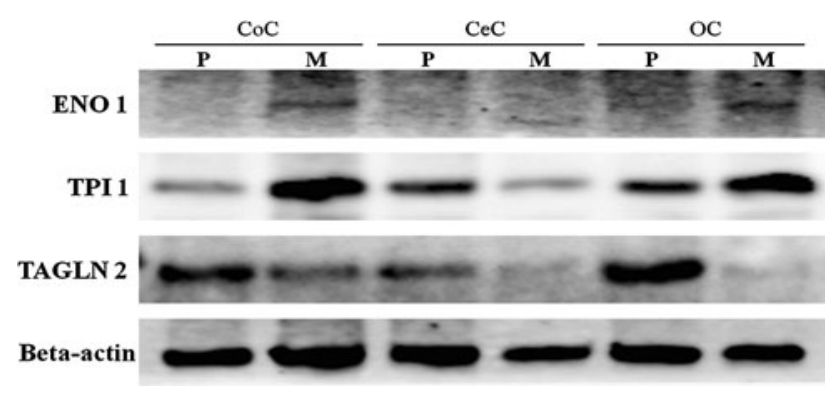

Fig. 2 Western blot analysis of ENO1, TPI-1, and TAGLN2. Proteins from primary and metastatic tumors were separated by SDS-PAGE and transferred to PVDF membranes, followed by detection using the respective primary antibodies and an HRPconjugated secondary antibody. In endometrial and ovarian cancers, the expression of ENO1 and TPI-1 was higher in metastatic tumors than in primary tumors, and the expression of TAGLN2 was lower in metastatic tumors than in primary tumors. Further, in cervical cancer, the expression of TPI-1 and TAGLN2 was lower in metastatic tumors than in primary tumors. $P$ primary tumors, $M$ metastatic tumors

In addition, immunohistochemical analysis was employed to assess ENO1. Figure 3 shows representative examples of immunostaining for ENO1 in primary and metastatic tumors. Both western blotting and immunohistochemistry confirmed the findings of LC-MS/MS analysis.

\section{Discussion}

The aim of this study was to identify biomarkers for brain metastases of gynecological malignancies, which have a different protein expression profile compared with primary tumors. Identification of proteins that are up-regulated or down-regulated in metastatic tumors may facilitate the detection and/or treatment of metastasis cancer. Therefore, we performed a comparative proteomic analysis of primary and metastatic gynecological cancers by LC-MS/MS analysis of proteins extracted from FFPE samples. Western blotting and immunohistochemistry were also performed to confirm the results of LC-MS/MS analysis. Until recently, protein extraction from formalin-fixed tissues was thought to be impossible because fixation by formalin creates strong intermolecular covalent bonds [24]. However, successful protein extraction protocols have been established based on the heat-induced antigen retrieval technique widely applied for immunohistochemistry and proteomic analysis by LC-MS/MS $[25,26]$. In the present study, the protein expression profile of metastatic tumors was compared with that of primary tumors using extracts of FFPE samples. By LC-MS/MS and scaffold analysis, 76 proteins were identified in 3 primary tumors and 101 proteins were found in 3 metastatic tumors. These proteins were related to a variety of biological processes (Fig. 1b). To find candidate proteins, the 129 proteins that we identified were divided into 15 categories based on biological processes. Comparison of the distribution of these proteins between the primary and metastatic tumors showed differences in the expression of proteins related to metabolic, developmental, and multicellular organismal processes (Fig. 1c). Eight candidate proteins were selected that were predominantly or exclusively expressed by either the primary or metastatic tumors (Table 3). Several of the proteins identified in this study have been reported previously as possible metastasis-related proteins, including TAGLN2, 


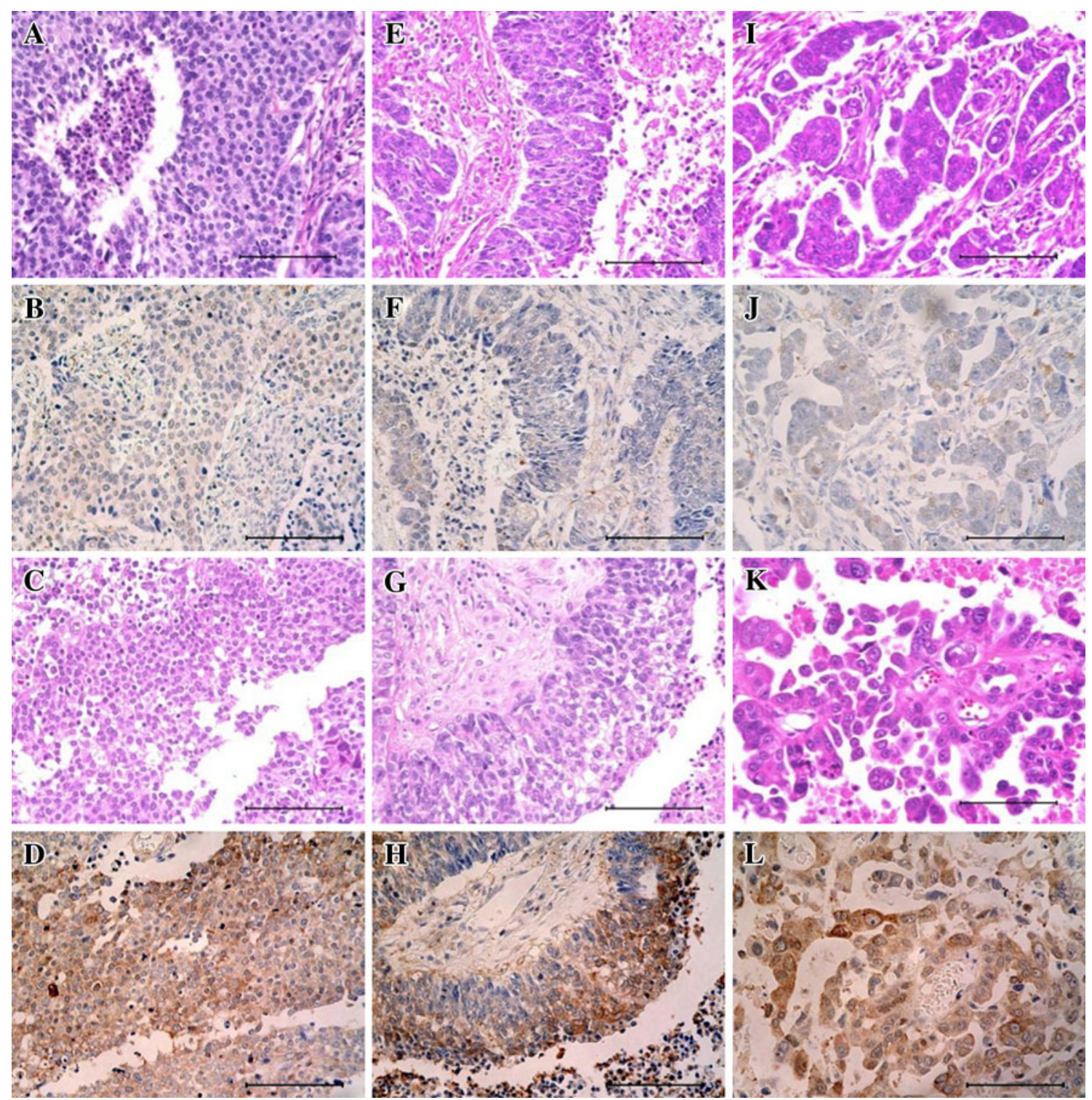

Fig. 3 Representative immunostaining of ENO1 in primary and metastatic tumors. $\mathbf{a}, \mathbf{b}, \mathbf{e}, \mathbf{f}, \mathbf{i}$, and $\mathbf{j}$ show primary tumors. $\mathbf{c}, \mathbf{d}, \mathbf{g}, \mathbf{h}$, $\mathbf{k}$, and $\mathbf{l}$ show metastatic tumors. $\mathbf{a}, \mathbf{e}, \mathbf{i}, \mathbf{c}, \mathbf{g}$, and $\mathbf{k}$ show HE staining. $\mathbf{b}, \mathbf{f}, \mathbf{j}, \mathbf{d}, \mathbf{h}$, and $\mathbf{l}$ show ENO1 staining. ENO1 is overexpressed in

TPI-1, ENO1, phosphatidylethanolamine binding protein (PEBP1), and mitochondrial ATP synthase alpha-subunit (ATP5A). TAGLN2 is a poorly characterized member of the calponin family. Its closest homologue is Transgelin 1/SM22a, an actin cross-linking protein [27] that is thought to undergo down-regulation as an early marker of transformation [28]. A recent study suggested that TAGLN2 has a negative influence on metastasis suppressing the invasive capacity of tumor cells [23]. TPI-1 is an enzyme that catalyzes the reversible transformation of D-3-glyceraldehyde phosphate into dihydroxyacetone phosphate. Dihydroxyacetone phosphate is then transformed into D-3-glyceraldehyde phosphate to continue the glycolytic pathway, so metastatic tumors. All images are $\times 400$ magnification. Scale bars $100 \mathrm{~mm} . E C$ endometrial cancer (a-d). $C e C$ Uterine cervical cancer (e-h). $O C$ ovarian cancer $(\mathbf{i}-\mathbf{l})$

TPI-1 has an important role in the process of glycolysis [29]. Changes of enzyme activity have been reported under normal and pathological conditions, and overexpression of TPI-1 may activate both energy production and protein synthesis/degradation in rapidly growing tumor cells [30]. Another study suggested that metabolic changes are associated with markedly enhanced survival and proliferation of breast cancer in the brain metastasis [21]. ENO1 is a glycolytic enzyme that catalyzes the conversion of 2-phosphoglycerate into phosphoenolpyruvate [31]. ENO1 is the frequently deregulated in various types of cancer [32]. In addition, ENO1 is more highly expressed in metastatic cancer cells compared with primary cancer cells, 
suggesting an oncogenic role of ENO1 [22]. PEBP1 was originally identified as an endogenous inhibitor of Raf, and it negatively regulates the Raf/MEK/ERK-signaling cascade [33]. It has been well established that PEBP1 suppresses the metastatic spread of tumor cells, and, moreover, the down-regulated expression of PEBP1 is observed in a number of human cancers [34]. ATP5A was identified in tumor metastasized to liver and was overexpressed in metastatic tumor [35].

These reports indicated that there are several changes of protein expression between primary and metastatic tumor, and the metastasis may be supported by the expression changes. In the present study of clinical tumor samples, we identified the expression of TAGLN2 in primary tumors and we also identified TPI-1 and ENO1 in metastatic tumors, predominantly by LC-MS/MS. Although the three proteins identified in this study have previously been suggested to be cancer-related, their functional role in gynecological cancer remains controversial. Also, we investigated the three proteins by western blotting. There were a few disparities in the results between western blot and LC-MS/MS. We described that TPI-1 was predominantly identified in metastatic tumors. However, the TPI-1 expression in primary tumor was higher than metastatic tumor in cervical cancer. It has been reported that TPI-1 was represented overexpression in tumor cells [30]. In addition, the overexpression of TPI-1 in metastatic tumor may not be a necessary character for metastasis. In any case, difference of cancer type may indicate difference of metastatic character. Further study is necessary to obtain their credibility as biomarkers.

Various molecular and genetic changes occur during the multistep process of tumor dissemination, and these have been called the "metastatic cascade" [2]. This cascade starts with escape from the primary tumor by invasion of the surrounding tissue, entry into the bloodstream (intravasation), extravasation at a distant site, and finally survival and proliferation to form metastases [36, 37]. In this study, expression of TPI-1 and ENO1, which enhances cancer cell survival and proliferation, were higher in metastatic tumors than in primary tumors, and TAGLN2, which suppresses invasion of cancer cells, was lower in metastatic tumors than in primary tumors. The different expression of these proteins between primary and metastatic tumor may require characteristics for brain metastasis in these gynecological cancers. In addition, tubulin beta, $60 \mathrm{~S}$ ribosomal protein L7 and Myosin light chain 6B were also identified in this study. Their role in tumor metastasis requires further investigation, but the role may be similar to that of proteins such as TPI-1, ENO1, and TAGLN2.

A recent study indicated that primary tumors can be regarded as genetically heterogeneous and contain subpopulations of cells with varying levels of metastatic potential [38]. The data indicate that primary tumors are subpopulations of cells with different characteristics. This study indicated, by difference of identified proteins, that cancer cells can have different characteristics between primary tumors and metastatic tumors. The different characteristics might relate to brain metastasis in this study.

In conclusion, we identified several proteins that may be involved in brain metastasis of gynecological malignancies. Since our study consisted of a small number of patients, a larger study should be conducted in order to define the biological functions and influence in tumorigenesis and metastasis. In this study, we demonstrated the biomarker analysis tool using FFPE tissue-based proteomics by comparison of expression protein. Future studies using this tool will contribute to analysis of biomarkers, not only brain metastasis but also other organ metastasis such as lung and lymph node.

Acknowledgments Hiroyumi Nishikawa is thanked for technical assistance.

Open Access This article is distributed under the terms of the Creative Commons Attribution License which permits any use, distribution, and reproduction in any medium, provided the original author(s) and the source are credited.

\section{References}

1. Matsuda T, Marugame T, Kamo K, et al. Cancer incidence and incidence rates in Japan in 2005: based on data from 12 populationbased cancer registries in the Monitoring of Cancer Incidence in Japan (MCIJ) project. Jpn J Clin Oncol. 2011;41:139-47.

2. Fidler IJ. Critical factors in the biology of human cancer metastasis: twenty-eighth G.H.A. Clowes memorial award lecture. Cancer Res. 1990;50:6130-8.

3. Hirohashi S. Inactivation of the E-cadherin-mediated cell adhesion system in human cancers. Am J Pathol. 1998;153:333-9.

4. Nathoo N, Chahlavi A, Barnett GH, Toms SA. Pathobiology of brain metastases. J Clin Pathol. 2005;58:237-42.

5. Paget S. The distribution of secondary growths in cancer of the breast. 1889. Cancer Metastasis Rev. 1989;8:98-101.

6. Fagundes H, Perez CA, Grigsby PW, Lockett MA. Distant metastases after irradiation alone in carcinoma of the uterine cervix. Int J Radiat Oncol Biol Phys. 1992;24:197-204.

7. Mariani A, Webb MJ, Keeney GL, et al. Hematogenous dissemination in corpus cancer. Gynecol Oncol. 2001;80:233-8.

8. Anupol N, Ghamande S, Odunsi K, et al. Evaluation of prognostic factors and treatment modalities in ovarian cancer patients with brain metastases. Gynecol Oncol. 2002;85:487-92.

9. Committee of Brain Tumor Registry of Japan. Report of Brain Tumor Registry of Japan (1969-1996). Neurol Med Chir (Tokyo) 2003;43 Suppl:i,vii, 1-111.

10. Kolomainen DF, Larkin JM, Badran M, et al. Epithelial ovarian cancer metastasizing to the brain: a late manifestation of the disease with an increasing incidence. J Clin Oncol. 2002;20:982-6.

11. Perou CM, Sorlie T, Eisen MB, et al. Molecular portraits of human breast tumours. Nature. 2000;406:747-52.

12. Cravatt BF, Sorensen EJ. Chemical strategies for the global analysis of protein function. Curr Opin Chem Biol. 2000;4:663-8. 
13. Roesli C, Borgia B, Schliemann C, et al. Comparative analysis of the membrane proteome of closely related metastatic and nonmetastatic tumor cells. Cancer Res. 2009;69:5406-14.

14. Hanahan D, Weinberg RA. The hallmarks of cancer. Cell. 2000;100:57-70.

15. Yu Y, Shen H, Yu H, et al. Systematic proteomic analysis of human hepotacellular carcinoma cells reveals molecular pathways and networks involved in metastasis. Mol BioSyst. 2011;7:1908-16.

16. Thongwatchara P, Promwikorn W, Srisomsap C, et al. Differential protein expression in primary breast cancer and matched axillary node metastasis. Oncol Rep. 2011;26:185-91.

17. Yao $\mathrm{H}$, Zhang Z, Xiao Z, et al. Identification of metastasis associated proteins in human lung squamous carcinoma using two-dimensional difference gel electrophoresis and laser capture microdissection. Lung Cancer. 2009;65:41-8.

18. Shi SR, Liu C, Balgley BM, et al. Protein extraction from formalin-fixed, paraffin-embedded tissue sections: quality evaluation by mass spectrometry. J Histochem Cytochem. 2006;54:739-43.

19. Gregory JD, Sajdera SW. Interference in the Lowry method for protein determination. Science. 1970;169:97-8.

20. Keller A, Nesvizhskii AI, Kolker E, Aebersold R. Empirical statistical model to estimate the accuracy of peptide identifications made by MS/MS and database search. Anal Chem. 2002;74:5383-92.

21. Chen EI, Hewel J, Krueger JS, et al. Adaptation of energy metabolism in breast cancer brain metastases. Cancer Res. 2007;67:1472-86.

22. $\mathrm{Wu} \mathrm{W}$, Tang $\mathrm{X}, \mathrm{Hu} \mathrm{W}$, et al. Identification and validation of metastasis-associated proteins in head and neck cancer cell lines by two-dimensional electrophoresis and mass spectrometry. Clin Exp Metastasis. 2002;19:319-26.

23. Duran MC, Vega F, Moreno-Bueno G, et al. Characterisation of tumoral markers correlated with ErbB2 (HER2/Neu) overexpression and metastasis in breast cancer. Proteomics Clin Appl. 2008;2:1313-26.

24. Rait VK, Xu L, O'Leary TJ, Mason JT. Modeling formalin fixation and antigen retrieval with bovine pancreatic RNase A II. Interrelationship of cross-linking, immunoreactivity, and heat treatment. Lab Invest. 2004;84:300-6.

25. Prieto DA, Hood BL, Darfler MM, et al. Liquid Tissue: proteomic profiling of formalin-fixed tissues. BioTechniques 2005;Suppl:32-5.
26. Ono A, Kumai T, Koizumi H, et al. Overexpression of heat shock protein 27 in squamous cell carcinoma of the uterine cervix: a proteomic analysis using archival formalin-fixed, paraffinembedded tissues. Hum Pathol. 2009;40:41-9.

27. Shapland C, Hsuan JJ, Totty NF, Lawson D. Purification and properties of transgelin: a transformation and shape change sensitive actin-gelling protein. J Cell Biol. 1993;121:1065-73.

28. Shields JM, Rogers-Graham K, Der CJ. Loss of transgelin in breast and colon tumors and in RIE-1 cells by Ras deregulation of gene expression through Raf-independent pathways. J Biol Chem. 2002;277:9790-9.

29. Robert J, van Rymenant M, Lagae F. Enzymes in cancer. III. Triosephosphate isomerase activity of human blood serum in normal individuals and in individuals with various pathological conditions. Cancer. 1961;14:1166-74.

30. Zhang D, Tai LK, Wong LL, et al. Proteomic study reveals that proteins involved in metabolic and detoxification pathways are highly expressed in HER-2/neu-positive breast cancer. Mol Cell Proteomics. 2005;4:1686-96.

31. Pancholi V. Multifunctional alpha-enolase: its role in diseases. Cell Mol Life Sci. 2001;58:902-20.

32. Hamaguchi T, Iizuka N, Tsunedomi R, et al. Glycolysis module activated by hypoxia-inducible factor 1alpha is related to the aggressive phenotype of hepatocellular carcinoma. Int J Oncol. 2008;33:725-31.

33. Yeung K, Seitz T, Li S, et al. Suppression of Raf-1 kinase activity and MAP kinase signalling by RKIP. Nature. 1999;401:173-7.

34. Granovsky AE, Rosner MR. Raf kinase inhibitory protein: a signal transduction modulator and metastasis suppressor. Cell Res. 2008;18:452-7.

35. Chang HJ, Lee MR, Hong SH, et al. Identification of mitochondrial FoF1-ATP synthase involved in liver metastasis of colorectal cancer. Cancer Sci. 2007;98:1184-91.

36. Christiano AP, Yoshida BA, Dubauskas Z, et al. Development of markers of prostate cancer metastasis. Review and perspective. Urol Oncol. 2000;5:217-23.

37. MacDonald NJ, Steeg PS. Molecular basis of tumour metastasis. Cancer Surv. 1993;16:175-99.

38. Navin N, Kendall J, Troge J, et al. Tumour evolution inferred by single-cell sequencing. Nature. 2011;472:90-4. 